\title{
THE GREAT RESET E AS STARTUPS: NOVAS RELAÇÕES DE TRABALHO NO CAPITALISMO CONTEMPORÂNEO
}

\author{
Recebido em 5/04/2021, aprovado em 31/05/2021 \\ 10.30612/mvt.v8i14.15023 \\ João Fernando de Lima Parra ${ }^{1}$
}

\begin{abstract}
RESUMO: A ideia do the great reset, preconizada pelo 51 Fórum Econômico Mundialde 2021,tem incluído naagenda uma nova forma de se pensar o capitalismo que exigirá uma grande mudança em suas bases estruturais. Este artigo visa contribuir com o debate de como as startups, neste contexto, podem ser vistas como um elemento disruptivo por se diferenciarem das corporaçóes tradicionais originando novas relaçóes de trabalho. O objetivo é traçar um percurso teórico que busca entender as bases do surgimento tanto deste modelo de empresa quanto do seus criadores, os empreendedores inovadores. Veremos que assubjetividades desses empreendedores vêm sendo mobilizadas pelo componente ideológico das startups, reforçando o seu enquadramento ao capitalismo preconizado pelo Fórum.Conclui-se que, por trás de todo este manto ideológico, os modos de extração de mais-valia se mantém, se diferenciando em sua aparência, mas não em sua essência.
\end{abstract}

Palavras-chave: Startups. Precarização do trabalho. Empreendedores. Fórum Econômico Mundial.

\section{THE GREAT RESETAND STARTUPS: NEW WORKING RELATIONSHIPS IN CONTEMPORARY CAPITALISM}

ABSTRACT: The idea of the great reset advocated by the 51st World Economic Forum in 2021 has included on the agenda a new way of thinking about capitalism that will require a major change in its structural bases. This article aims to contribute to the debate on how startups, in this context, can be seen as a disruptive element for differentiating themselves from traditional corporations creating new work relationships. The objective is to outline a theoretical path that seeks to understand the basis for the emergence of both this company model and its creators, innovative entrepreneurs. We will see that their subjectivities have been mobilized by the ideological component of startups, reinforcing their framework to the capitalism recommended by the Forum. It is concluded that behind all this ideological cloak, the ways of extracting surplus value are maintained, differing in appearance, but not in essence.

Keywords: Startups. Precarious work. Entrepreneurs. World Economic Forum.

1 Bacharel em Marketing e Propaganda pela Universidade Norte do Paraná (2007), Bacharel em Sociologia pela Fundaçáo Escola de Sociologia e Política de São Paulo (2016), Mestre em Marketing e Investigación de Mercados pela Universitat de València (2009), Mestre em Ciências Sociais pela Universidade Estadual de Londrina (2019) e Doutorando em Sociologia pela Universidade Estadual de Londrina. Integrante do Grupo de Estudos sobre Novas Tecnologias e Trabalho (GENTT/UEL). Email: joaoparra@hotmail.com. 


\section{THE GREAT RESETY LAS STARTUPS: NUEVAS RELACIONES DE TRABAJO EN EL CAPITALISMO CONTEMPORÁNEO}

RESUMEN:La idea del the great reset que propone el 51 Foro Económico Mundial en 2021 ha incluido en la agenda una nueva forma de pensar el capitalismo que requerirá un cambio importante en sus bases estructurales. Este artículo tiene como objetivo contribuir al debate sobre cómo las startups, en este contexto, pueden verse como un elemento disruptivo para diferenciarse de las corporaciones tradicionales creando nuevas relaciones laborales. El objetivo es trazar un camino teórico que busque comprender las bases del surgimiento tanto de este modelo de empresa como de sus creadores, emprendedores innovadores. Veremos que sus subjetividades han sido movilizadas por el componente ideológico de las startups, reforzando su marco al capitalismo recomendado por el Foro. Se concluye que detrás de todo este manto ideológico se mantienen las formas de extracción de plusvalía, diferenciándose en apariencia, pero no en esencia.

Palabras Clave: Startups. Trabajo precario. Empreendedores. Foro Econômico Mundial.

\section{INTRODUÇÃO}

O tema do $51^{\circ}$ Fórum Econômico Mundial (FEM), de 2021, foi the great reset e incluiu no centro do debate a necessidade de uma grande mudança nas bases estruturais do capitalismo tal como conhecemos. Nas palavras do seu fundador e Presidente Executivo, Klaus Schwab:

Temos que restaurar um sistema funcional de cooperação global inteligente estruturado para enfrentar os desafios dos próximos 50 anos. The Great Reset exigirá que integremos todos os stakeholders da sociedade global em uma comunidade de interesse, propósito e ação em comum. Precisamos de uma mudança de mentalidade, passando do pensamento de curto para o de longo prazo, passando do capitalismo de shareholder para a responsabilidade de stakeholder (FAVARETO, 2020, online).

O modelo de capitalismo que a organização preconiza tem a ver com a transiçáo de um capitalismo de shareholder, que visa à lucratividade em curto prazo com foco na rentabilidade dos acionistas, para um capitalismo de stakeholder com foco nas empresas, funcionários, clientes e práticas sustentáveis.

Este artigo visa contribuir com o debate de como as startups, neste contexto, podem ser vistas como um elemento disruptivo por se diferenciarem das corporaçôes tradicionaisoriginando novas relaçôes de trabalho. Este modelo pode ser definido² como: "um tipo de microempresa concei-

$2 \quad$ Há uma imensa dificuldade em encontrar uma definição consensual do termo startup. De acordo com um especialista no Vale do Silício - local onde nasceu o termo e ainda é referência para empresas do setor - Reinaldo Normand (2014, p. 9) "pergunte a dez pessoas o que é uma startup e você provavelmente obterá respostas diferentes". A definição utilizada aqui toca em duas bases importantes que são a replicabilidade e escalabilidade que, de acordo com o Normand (2014), são aspectos centrais para definir se uma empresa grande e capitalizada pode ou não ser considerada startup. Em seu livro Vale do silício: entenda como funciona a regiāo mais inovadora do planeta (2014) são apresentados dois exemplos que ajudam a ilustrar essa lógica: o Pinterest ainda é considerado uma startup, pois ainda não encontrou um modelo de negócios que gere receitas de formas sustentadas no longo prazo, ou seja, ainda náo encontrou a replicabilidade do seu modelo de negócios. No caso do Facebook, seu modelo escalável e repetível já está consolidado e não pode mais ser considerado uma startup. 
tuada como nascente, com até cinco anos de existência, e destinada à captação de recursos para o desenvolvimento de produtos replicáveis e escaláveis a partir de projetos selecionados por tempo determinado" (BICUDO, 2016, online).

Os efeitos mais visíveis de como as startups têm revolucionado o capitalismo contemporâneo podem ser vistos nos aplicativos de transporte e entregas, cujos exemplos mais célebressão Uber e Ifood, pois desvinculam, de uma maneira inédita, o empregador do empregado, colocando o aplicativo com uma ponte entre oferta e demanda. O tema da exploração do trabalho nestes aplicativos vem sendo desenvolvido em uma extensa bibliografia (ANTUNES; FILGUEIRAS, 2020, FONTES, 2017).

O objetivo aqui é elucidar não os resultados diretos destes novos tipos de vínculos trabalhistas, mas jogar luz ao trabalho dos criadores das startups, os empreendedores inovadores ${ }^{3}$ etraçar um percurso teórico que visa entender as bases do surgimento tanto deste modelo de empresa como do empreendedora ela associado. Veremos que mesmo "revolucionando" as dinâmicas capitalistas,suas bases estão calcadas em formas de exploração semelhantes que vestem apenas uma roupagem diferente, relacionando-a a aspectos subjetivoscomo "fazer o bem" ou "mudar o mundo".

Para cumprir com o objetivo proposto, primeiramente será apresentada a definição do capitalismo de stakeholder e o contexto em que foi desenvolvido. Após esta etapa preliminar, focaremos nas startups, em especial como o seu surgimento ensejou novas relaçóes laboraise modificou o discurso do empreendedorismo. Depois desteenquadramento histórico, nos centraremos especificamente nos empreendedores inovadores enooutro lado das startups, com a finalidade de delinear a realidade por trás do discurso idealizado e romântico. Nas consideraçôes finais serão traçados possíveis cenários futuros.

\section{O CAPITALISMO DE STAKEHOLDER}

Antes de definir as bases conceituais do modelopreconizado pelo FEM, cabe uma breve contextualização da criação do próprio Fórum e sua relevância para o capitalismo mundial.

\section{A HISTÓRIA DO FÓRUM ECONÔMICO MUNDIAL}

O Fórum Econômico Mundial é uma organização sem fins lucrativos, fundada em 1971 por Klaus Martin Schwab e tem como objetivo estabelecer a cooperação público privado através do engajamento dos principais líderes políticos e empresariais para a criação de agendas globais, regionais, industriais e com isso "melhorar a situação do mundo", segundo a definição da própria organização (WORLD ECONOMIC FORUM, 2021, online). O FEM é mundialmente conhecido pelo encontro anual na cidade Suíça de Davos, no entanto, o Fórum também organiza um série de outros eventos como a Reuniáo Mundial dos Novos Campeóes, na China e vários outros encontros regionais. Pode-se destacar sua atuação na produção de relatórios de pesquisa em setores específicos, bem como iniciativas de fomento a jovens lideranças eaçóes sociais.

A princípio a organização se chamava Simpósio Europeu de Administração e era exclusivamente focada em intercâmbio de experiências entre empresários europeus e na introdução de modelos americanos de organização empresarial, uma vez que seu criador Klaus Schwabestudou nos Estado

3 Utilizamos a expressão "empreendedorismo inovador" para diferenciar do empreendedorismo "tradicional" vinculados a profissionais liberais/autônomos como cabelereiros, pintores, camelôs, etc. A definição utilizada aqui está relacionada a atividades que se dedicam "à geraçáo de riquezas, seja na transformaçáo de conhecimentos em produtos ou serviços, na geraçáo do próprio conhecimento ou na inovação em áreas como: marketing, produção, organizaçáo etc.” (LOURES, 2015, p. 93). 
Unidos e se mostrava como um grande entusiasta da organizaçáo empresarial americana. Foi só a partir de 1974 que a organização ganha os contornos que conhecemos hoje,quando políticos passaram a ser convidados e, assim, se ampliou o âmbito das discussões, incluindo pautas socioeconômicas. Em 1987, a organização mudou seu o nome para Fórum Econômico Mundial e vem ganhando notoriedade desde então. O sucesso não veio isento de críticas, a partir do final dos anos 1990 e início dos anos 2000, pois foi alvo de intensos protestos, levando o governo da Suíça a aumentar os gastos com segurança. Como um resultado direto destas críticas foi criada o que podemos chamar de sua antítese: o Fórum Social Mundial, que foi realizado pela primeira vez emPorto Alegre, em 2001.

O FEM, assim como outras organizaçóes internacionais, pode ser enquadrado na categoria de estrutura mundial de poder ${ }^{4}$, uma vez que reúne membros de uma elite com poder decisório e influência para formular agendas e políticas públicas. Mesmo sendo considerada uma estrutura de poder (IANNI, 1998), ainda não tem a mesmainfluência das "transnacionais tradicionais, [tais como o Fórum Econômico Mundial/] FMI, Banco mundial, [Organização Mundial da Saúde/] OMS que dispóem de recursos financeiros técnicos e organizacionais, mobilizando ciência e técnica, equipes e aparatos, para diagnosticas, planejar e pôr em pratica decisóes que influenciam as economias dos países, e consequentemente a economia mundial como um todo" (IANNI, 1998, p. 29). Embora não disponha da mesmaautoridade a nível político, a capacidade de criação de hegemonia do FEM tem um peso significativo (D'ANDRETA, 2018), pois se trata de uma instituiçáo capitalista que faz críticasàs próprias bases do modelo, tocando em questôes nodais como a lucratividade e o interesse dos acionistas.

Veremos que a mudança rumo a outro capitalismo vem diante da necessidade de se fazer frente a um duplo impasse, resultado da maior crise sanitária dos últimos 100 anos e do alto endividamento dos países, sem precedentes em tempos de paz na história mundial (STUBBINGTON, 2019). Nas palavras de Klaus Schwab (2019, online) "a pandemia representa uma rara, mas estreita, janela de oportunidade para refletir, reimaginar e resetar o nosso mundo para criar um mundo mais saudável, justo e prospero".

\section{THE GREAT RESET}

O conceito de capitalismo de stakeholder não é novo e acompanha Klaus Schwab desde a criação do Fórum. $\mathrm{O}$ autor, na época um jovem acadêmico, via nas atitudes do pai, empresário na cidade alemã de Ravenburg, uma preocupação real com a opiniáo de seus empregados, com os clientes e fornecedores. Da mesma forma sua empresa, Escher Wyss, tinha um real compromisso com a cidade em que estava instalada, em uma condição de respeito mútuo com as diversas instituiçóes locais. Toda esta experiência de respeito com os diversos stakeholders foi descrita em seu primeiro livro, Modern Company Management in Mechanical Engineering (1971).

O termo ganhou especial relevância em países social democratas, principalmente os nórdicos, que ainda conservavam as bases do Estado de Bem Estar Social, entre elas o modelo tripartite de negociação trabalhista que incluíam empresários, governos e trabalhadores (SCHWAB, VANHAM, 2021). No entanto, o modelo sofreu impactantes adaptações a partir dos anos 1980 e foi se

$4 \quad$ Organizaçóes, formalmente independente de estados nacionais, que tem a capacidade de estabelecer critérios e diretrizes os quais devem se ajustar-se os governos nacionais (BANCO MUNDIAL, 1996). 
extinguindo pela ascensão do neoliberalismo ${ }^{5}$ e do chamado capitalismo de shareholder baseado nas concepções de Milton Friedman de "the business of business in business" ${ }^{\text {, }}$, que consolidou a prevalência de um modelo focado em acionistas e na rentabilidade a curto prazo. Segundo Schwab (2019), esta é concepção hegemônica na maioria dos países ocidentais e domina a mentalidade empresarial das corporaçóes.

Diante da janela de oportunidades fornecida pelo atual impasse, o autor reposiciona seu conceito, agora sem as mesmas bases dos anos 1970, sendo convertido em um novo "capitalismo de stakeholder do século 21 ou simplesmente capitalismo de stakeholder" (SCHWAB, VANHAM, 2021, p.198). O conceito se coloca como uma terceira via ${ }^{7}$ entre o atual formato hegemônico nos países ocidentais, mencionado acima, e o modelo de capitalismo de Estado, que confia ao governo a condução da economia. Este formatovem ganhando destaque em muitos mercados emergentes, especialmente na China.

$\mathrm{O}$ autor admite que as duas formas geraram um "tremendo progresso econômico nas últimas décadas e nos deixaram com um mundo que é mais próspero do que nunca" (SCHWAB, VANHAM, 2021, p. 194). A questão é que os dois "levaram ao aumento das desigualdades de renda, riqueza e oportunidades; tensóes aumentadas entre os que têm e os que não têm; e, acima de tudo, uma degradação em massa do meio ambiente" (SCHWAB, VANHAM, 2021, p. 194). Entre estes dois modelos o capitalismo de stakeholder busca fazer frentes as tensôes mencionadas e principalmente na concentração de poder, seja dos shareholder, na figura dos acionistas, seja na condução centralizada da economia pelos governos.

Esta terceira via permite a existência de certo equilibro entre as partes interessadas sem que nenhuma se sobreponha sobre as demais, além de colocar em perspectiva "um objetivo mais amplo do que os lucros: a saúde e a riqueza das sociedadesem geral, bem como do planeta e das geraçóes futuras" (SCHWAB, VANHAM, 2021, p. 196). A agenda para a implementação da terceira via, ou melhor, do the great reset, pressupóe três componentes: direcionar o mercado para resultados mais justos. Garantir que os investimentos avancem para objetivos compartilhados com equidade e sustentabilidade e aproveitar as inovaçóes da quarta revolução industrial ${ }^{8}$ para apoiar o bem público abordando os desafios sociais e da saúde (SCHWAB, 2019). Schwab entende que, além do impasse relacionado à pandemia e a crise fiscal, estamos testemunhando, concomitantemente a este processo, uma mudança comportamental geracional, que ele mesmo denomina como "efeito Greta” (SCHWAB, 2020), se referindo a jovem ativista Sueca Greta Thunberg, que já foi convidada

\footnotetext{
5 É prudente ressaltar que o debate a respeito do que é o neoliberalismo é amplo e não é o objetivo deste artigo aprofundar no tema. Para mais informaçóes o professor Daniel Pereira Andrade (2019) faz um recorrido interessante sobre as vertentes e o uso do termo no artigo "O que é o neoliberalismo? A renovação do debate nas ciências sociais".

6 A traduçáo literal seria "O negócio do negócio é o negócio", mas seu significado perpassa a ideia de que as empresas devem funcionar única e exclusivamente com foco na lucratividade.

7 Importante deixar claro que a concepçáo do autor segue a linha do liberalismo econômico e em nenhum momento se propóe a romper com o livre mercado. Nas palavras do próprio Klaus Schwab "capitalismo na definição tradicional da palavra: indivíduos e as empresas privadas representam a maior parte da economia. Isto é, eu acredito, um requisito para um sistema econômico sustentável: indivíduos privados e as empresas devem ser capazes de inovar e competir livremente" (SCHWAB, VANHAM, 2021, p. 196).

$8 \quad$ Há um amplo debate sobre até que ponto existe a quarta revolução industrial ou ela ainda é uma extensão da terceira (RIFKIN, 2002), ou mesmo algo novo que não pode ser descrito como uma "etapa" das transformaçóes do modelo produtivo desde o séc. 18 (DOWNBOR, 2020), no entanto, Klaus Schwab (2016) em seu livro A quarta revolução industrial (2016) sustenta que não se trata somente de um aspecto da terceira e três razóes sustentam sua convicção: 1) a velocidade, pois ao contrário das anteriores, esta evolui em um ritmo exponencial e náo linear. 2)amplitude e profundidade, pois a revoluçáo nấo muda apenas "o que" e o "como" fazemos as coisas, mas no limite seus impactos mudaram quem somos e a 3) impacto sistêmico, ela envolverá transformaçáo de sistemas inteiros entre países e dentro deles, em empresas, indústria e toda a sociedade.
} 
por ele duas vezes para discursar no Fórum. Greta representa a geração $Z^{9}$, que tem uma especial preocupação com o meio ambiente e a responsabilidade social.

Neste sentido, a continuação,o artigo propóe debater como as startups podem ser o novo tipo de empresa que essa configuração necessita,uma vez que elas entram na agenda como forma de utilizar a tecnologia para fazer frente aos desafios atuais, ao representar a nova geraçáo $\mathrm{Z}$ em seus empreendedores e buscar este objetivo mais amplo, mencionado por Schwab,de ser que uma empresa que vai além dos lucros.

\section{STARTUPS E AS NOVAS RELAÇÕES DE TRABALHO}

O surgimento do modelo de microempresa inovadora, que atualmente conhecemos como startup, só foi possível a partir dos anos 1990 (GITAHY, 2016). O modelo surgiu na esteira da globalização (potencializada a partir da queda do muro de Berlim), do advento da internet e da consolidação, a nível mundial, das doutrinas econômicas que podem ser denominadas de neoliberalismo. Contudo, foi só com a popularização da internet a partir dos anos 2000 que as startups puderam mostrar o seu lado revolucionário e não seria exagero dizer que nada voltou a ser como antes.

As redes sociais, os aplicativos de interaçôes instantâneas, as plataformas de compartilhamento: tudo isso, aliado à capilaridade que os smartphones ganharam, permitiu ao capitalismo colocar, literalmente, nas mãos de cada indivíduo um mundo infinito de possibilidades. Porém, o aspecto inovador destacado tem a ver com o potencial de transformar indivíduos comuns em "trabalhadores voluntários", borrando assim as linhas entre tempo de vida e tempo de trabalho. Todas as facetas da vida humana passam a ter poder de gerar valor para o capital.

A tese em que o capitalismousa o tempo de lazer do trabalhador como forma de se criar valor não é algo novo: vemos desde a escola de Frankfurt exemplos de como a indústria cultural contribui neste sentido (SILVA JUNIOR, 2019). Os avanços tecnológicos por si só têm o poder de transformar indivíduos em trabalhadores voluntários muito antes da explosão das startups. Vemos um exemplo de como este trabalho se concretiza em algo tão comum e corriqueiro como o uso do Internet Banking. Antes da possibilidade de se acessar os serviços por celular, era necessário estar fisicamente presente em uma agência para temas táo banais quanto verificar o saldo, fazer transferências e consultar o extrato da conta. Para abrir uma conta era necessário a interação com um funcionário e os boletos deveriam ser pagos no caixa. Hoje todas essas "tarefas" foram transferidas para o consumidor através da tecnologia, sem que ele o enxergue como tal e, mais importante ainda, se importe em fazê-lo, vendo a ação como uma comodidade. Algumas startups souberam aproveitar desse caráter impensado para fazer dele a sua própria razão de existir.

Veja o caso do Facebook, que todas as operaçôes são feitas por usuários de forma gratuita, assídua e espontânea, gerando enormes lucros em forma de dados quantificáveis e que geram publicidade -tudo isso em um empresa que tem como missão "dar às pessoas o poder de criar comunidades e aproximar o mundo" (PAYÃO, 2017, online). Neste aspecto "romântico" está a chave para entender o caráter disruptivo por trás da ascensão das startups e sua associação com o capitalismo de stakeholder: a lógica de transformar empresas em um mecanismo de resistência a este capitalismo

\footnotetext{
9 A Geração Z é a definição da geração de jovens nascidos após os anos 1990. A peculiaridade desta geração é que seu nascimento coincidiu com o advento da internet, entáo pode-se afirmar que são a primeira geraçáo a crescer em um mundo totalmente conectado e desde a infância já estão acostumados ao uso de computadores, smartphones, aplicativos de mensagens instantâneas, vídeo games... (SAVAGE, 2006)
} 
que só se importa com a lucratividade, através do uso da tecnologia para resolver problemas reais e mudar o mundo. Este sentido remete as condiçôes que permitiram o surgimento do próprio Vale do Silício, regiáo associada ao surgimento do modelo startup, e a ideologia californiana (BARBROOK; CAMERON 1996) a ele relacionada.

Antes de ser mundialmente conhecido como a meca da tecnologia mundial, o Vale do Silício ou, geograficamente, a região da baía de São Francisco, já foi um pequeno povoado de 200 habitantes que foi transformado em cidade pela corrida do ouro do séc. 19 - então pode-se afirmar que o próprio espírito empreendedor daqueles que se arriscavam a fazer fortuna contra todas as estatísticas foi determinante para a fundação do local (NORMAND, 2014). Já no séc. 20, a região foi um importante pólo industrial para a Marinha Americana e, via investimentos estatais, passou a concentrar também centros de pesquisa aeroespacial e de telecomunicaçóes. No entanto, foi apenas com o advento da Universidade de Stanford que ao fundar, em 1951, o polo industrial de tecnologia fez a região florescer atraindo as mentes mais brilhantes do país (NORMAD, 2014).

Em resumo, podemos dizer que o Vale do Silício foi uma convergência entre inovaçôes tecnológicas, grupos de profissionais qualificados e financiamento estatal em uma mistura de contra cultura, utopismo tecnológico e capitalismo liberal, base da ideologia californiana (BARBROOK; CAMERON, 1996) que gerou, com o passar dos anos, uma ideologia que pauta as subjetividades incidindo sobre o "desejo e afeto dos trabalhadores em relação ao próprio trabalho" (ZANON, 2017, p. 52), formando um profissional avesso a hierarquias tradicionais e propenso a fazer do risco um estilo de vida. Além disso, acreditam que um mundo melhor para todos é uma possibilidade reale depende apenas de seu trabalho e em sua fé em que as novas tecnologias levarãoao progresso e a mais liberdade para os indivíduos (BARBROOK; CAMERON 1996).

Este conceitoestá muito presente nos discursos do empreendedores inovadores que buscam um significado para a vida, como uma maneira de serem "desalienados" ${ }^{10}$ de um emprego, seguro, bem remunerado que, no entanto, não apresenta nenhum desafio e nenhuma possibilidade de se ver o "produto de seu trabalho". Essa promessa, ou sentido, pode ser considerada a uma nova face da exploração, pois, nas palavras de Deuleuze e Guattari (2011 apud ZANON, 2017, p. 108), a "produtividade do capital encontrou formas de manter-se revolucionária".

Diante do exposto, fica a indagação: como foi possível que as startups, um reflexo da nova fase do capitalismo e das novas formas de exploraçáo, conseguiram ser ressignificadas e transformadas em um empreendimento que alimenta os desejos dando ao trabalho um propósito revolucionário?

\section{EMPREENDEDORES DE STARTUP}

A startup como modelo de negócio gira entorno de uma ideia inovadora (BLANK; DORF, 2012; GITAHY, 2016), como ideias são incapazes de se concretizarem sozinhas, a figura do empreendedor é de fundamental importância para entendermos sua inserção no capitalismo contemporâneo. As bases para o que conhecemos como empreendedores inovadores foram colocadas, no início dos anos

\footnotetext{
10 Este conceito remete a uma transformação da aparência da "alienação" ao sentido de Marx (2005) nos Manuscritos Econômico-filosóficos. Como se essa nova relaçáo escamoteasse as dinâmicas de exploração por terem um "sentido" atribuído ao trabalho, introjetando a ideia de que não mais se enquadram mais na categoria de explorados ou pelo menos náo se enxergam nessa condição (ZANON, 2017).
} 
1970, nos processos denominados de acumulação flexível ${ }^{11}$ que culminaram na terceira revolução industrial e foram posteriormente consolidados com o advento da internet nos anos 1990.

A origem deste novo trabalhador precisa ser esclarecida em duas partes. A primeira delineia as transformaçóes tecnológicas e cientificas base para o que conhecemos como sistema Toyota de produção ${ }^{12}$ e as mudanças subjetivas e ideológicas derivadas desse modelo, que são um reflexo das tensôes nas relações capital trabalho que transpassavam os aspectos puramente econômicos para pautas relacionadas aos costumes e a liberdade individual (SIQUEIRA; COCCO, 2014, p. 219). A segunda parte é uma consequência destas mudanças agregadas ao corolário das transformaçôes dos anos 1990: a globalização; o surgimento da internet; a popularização dos computadores pessoais e dos smartphones, que moldaram as bases para as startupsse desenvolverem e influenciarem as relações laborais.

\section{SISTEMA TOYOTA DE PRODUÇÃO}

Os avanços tecnológicos e científicos significaram, na prática, uma alteração na lógica de produção de uma racionalidade fordista, puramente reprodutiva, de mercadorias padronizadas e produzidas por tecnologiasmecânicaspara um novo modelo, o Toyotismo que tem em seu cerne a questão da inovação aliada a processos tecnológicos (HARVEY, 1992). Este processo alterou uma das questôes chave do desenvolvimento do próprio capitalismo, que é a subsunção do trabalho à máquina (PRADO; PINTO, 2014) e foi o primeiro passo rumo à lógica flexível que está presente nos empreendedores inovadores.

As dinâmicas resultantes deste novo sistema de produção não estão regidasapenas pela busca da redução da jornada para aumentar a produtividade, como o modelo Taylorista/Fordista pressupunha. O Toyotismo está fora das amarras relacionadas ao tempo e ligado às práticas flexíveis que propóem que os trabalhadores se sintam parte da empresa e façam uso de recursos intelectuais ligados a criatividades e práticas inovadoras para aumentar a produtividade (ALVES, 2007). Neste contexto, os meios de produção cruciais deixam de ser principalmente as máquinas e os sistemas de máquinas que operam mediante a coerência mecânica. $\mathrm{O}$ aspecto mais crucial são os sistemas ativos de organização do conhecimento, que têm por base uma lógica cibernética que combina homens com máquinas (PRADO, 2005, p. 95). Como corolário, vemos que a produção opera com base em um "trabalho imaterial" 13 e que buscam constantemente inovaçôes tecnológicas na qual os trabalhadores detém uma nova racionalidade, derivada diretamente das tensôes nas relaçóes capital trabalho desse período.

\footnotetext{
11 O termo criado por David Harvey (1992) tem como objetivo explicar o processo de transiçáo do Fordismo para o pós-fordismo que ocorreu diante da incapacidade do modelo em conter as contradiçóes inerentes ao capitalismo, principalmente sob influência da primeira crise do petróleo, de 1973. Segundo o autor, a acumulaçáo flexível "é marcada por um confronto direto com a rigidez do fordismo. Ela se apoia na flexibilidade dos processos de trabalho, dos mercados de trabalho, dos produtos e padrôes de consumo. Caracteriza-se pelo surgimento de setores de produção inteiramente novos, novas maneiras de fornecimento de serviços financeiros, novos mercados e, sobretudo, taxas altamente intensificadas de inovaçáo comercial, tecnológica e organizacional". (HARVEY, 1992, p.140)

12 O toyotismo deriva de uma nova engrenagem na intensificaçáo do trabalho sob o modelo de produção flexível ou modelo just in time. O modelo se caracteriza pela "polivalência no trabalho em contraposição ao sistema Fordista, que se estruturava sobre a especializaçáo, ainda que limitada a uma operaçáo, a do operário. A polivalência implica um componente a mais de intensificação, à medida que se requer um esforço adicional de trabalho mental, conhecimento de operaçóes diversas, sua lógica de trabalho emotivo, concentração e atenção no controle de máquinas diversas" (DAL ROSSO, 2008, p.67).

13 A expressão trabalho imaterial é utilizada para designar um novo tipo de produção, baseado no conhecimento e em meios de trabalho automatizados. Segundo Gorz (2005, p. 29) esta transição "indica que o próprio conhecimento se tornou a principal força produtiva e que, consequentemente, os produtos da atividade social não são mais, principalmente, produtos do trabalho cristalizado, mas sim do conhecimento cristalizado. Indica também que o valor de trocas das mercadorias, sejam ou não materiais, não é determinado em última análise pela quantidade de trabalho social geral que elas contêm, mas, principalmente, pelo seu contudo de conhecimento, informaçôes, de inteligência gerais".
} 
O caso do Fordismo foi marcado por uma onda mundial de protestos nos anos 1960 e é fundamental para entender aspectos ideológicos vinculados aos trabalhadores que surgiram nesta transição. Houve uma mudança na concepção de sociedade tal como era preconcebida nos anos dourados do welfare state. Nesta nova concepção, o indivíduo ganha uma centralidade maior junto com a ideia de liberdade em contraposição a um Estado centralizador e planificado que regulava diversos aspectos da vida em sociedade. Este foco no indivíduo foi uma das bases precursoras da ideologia associada ao empreendedorismo inovador e dominante no mundo das startups.

Entre os protestos, as manifestaçôes estudantis de maio de 1968 na França foram os mais emblemáticos e colocaram no centro do debate a crítica ao aspecto regulador do Estado de bem estar social e ao trabalho nas fábricas (BIHR, 2007). Reivindicava-se uma maior liberdade em relação aos costumes esoluçóes para o desgastante trabalho repetitivo, fazendo com que fosse necessário repensar todo o modo de produção da época (CHESNAIS, 1996).

Foi no bojo de toda essa revolta que o neoliberalismo como ideologia econômica apropriou-se do discurso de "liberdade", a partir dos anos 1980, para difundi-lo no âmbito econômico, consolidando as bases do empreendedorismo que vê o indivíduo como um agente econômico centrado em si mesmo, que conhece os fenômenos normativos do mundo de modo perfeito e objetivo (PRADO, PINTO, 2014). Os indivíduos, segundo a doutrina, são a principal engrenagem de qualquer sociedade por sua capacidade inata de se desenvolver e empreender. Esta concepção foi habilmente utilizada por governos nos anos 1990, quando as políticas neoliberais mostravam seus efeitos mais nocivos em relação ao baixo crescimento das economias e as altas taxas de desemprego (HARVEY, 2014; KATZ, 2016).

O discurso difundido foi que em um mundo globalizado não há mais lugar para pessoas que querem depender de um emprego vitalício, ajuda do Estado ou qualquer outra subvenção a nível individual. Dessa forma, pensando a si próprios como uma empresa (DARDOT; LAVAL, 2016), o próprio indivíduo se torna o responsável pelo seu sucesso e, por uma lógica binária, de seu próprio fracasso, eximindo o Estado de qualquer forma de culpa ou compromisso. Veremos que os empreendedores inovadores compartilham estes valores e fazem deles o seu estilo de vida e, ao invés de enxergarem aspectos relacionados à falta de direitos e a insegurança como debilidades, as vê como algo natural, por exemplo, uma ferramenta para se manterem motivados.

\section{O SISTEMA "STARTUP DE PRODUÇÃO"}

A internet surge como uma invenção militar e começa a crescer vertiginosamente nos anos 1990, principalmente com a popularização dos computadores pessoais. O estrondoso sucesso começou a chamar a atençáo das empresas que rapidamente buscaram entrar no ciberespaço e de investidores que passaram a fazer um forte investimento especulativo. ${ }^{14} \mathrm{O}$ mercado financeiro testemunhava o aumento do valor das açóes de empresas de tecnologia como AOL, Yahoo e Amazon, que aumentavam rapidamente seu valor de mercado. O ápice dessa bonança foi compra da Time Warner pela AOL, uma das maiores negociaçóes da história da tecnologia ${ }^{15}$. No entanto, o valor de

\footnotetext{
14 Nos anos 1990, as indústrias de alta tecnologia e outras relacionadas ao setor da internet tiveram um crescimento exponencial, devido principalmente a grande quantidade de capital de risco disponível e criaram uma onda de crescimento no Vale do Silício. O mercado de açóes, como a NASDAQ, onde diversas corporaçóes voltadas para a tecnologia faziam parte da lista, experimentaram uma grande alta no preço de suas açóes (MANN; NUNES, 2009 apud ZANON, 2019).

15 A operação está entre as 10 maiores operaçóes de fusóes e aquisiçóes da história e ganhou as manchetes dos jornais por se tratar de uma compra náo usual, pois uma empresa da nova economia comprava uma tradicional do setor de entretenimento por US\$ 165 bilhões (MANZONI, 2017).
} 
mercado das empresas começou a se distanciar da realidade e o estouro da bolha foi só uma questão de tempo. Em março de 2000, foram sentidos os primeiros impactos e grande parte das empresas acabou saindo do mercado e suas açóes viraram pó.

Foi sob os escombros desta crise que o empreendedor inovador encontrou a sua razão de ser. Diante da onda de demissóes, principalmente de jovens qualificados, foi possível visualizar os primeiros traços deste novo trabalhador. $\mathrm{O}$ mercado foi inundado de desempregados que foram contratados sob o otimismo dos investimentos especulativos para inserir as empresas na era da internet e para substituir os trabalhadores menos qualificadosque não estavam adaptados a esta nova realidade. Estes trabalhadores acumulavam em seu currículo conhecimentos "mais qualificados, ligados a uma grande influência da demanda por tecnologia, ao fluxo de informaçóes e a cientificidade do mercado de trabalho" (ZANON, 2019, p. 30).

A comparação entre os desempregos nestas duas fases capitalistas pode ser diferenciada por uma "demanda toyotista intensificada" (ZANON, 2019, p. 31). Os primeiros desempregados deste novo padrão de acumulação foram derivados da substituição da força de trabalho por máquinas e de uma paulatina necessidade de qualificação técnica dos trabalhadores, associados a uma nova concepção de participação na empresa vinculada à criatividade. Já a segunda onda de desemprego provocada pela bolha do ponto.com requereu algo mais que a simples qualificação técnica, pois as empresas cada vez mais passaram a dar privilégio por profissionais que se disponibilizassem a um constante processo de inovação de seus próprios conhecimentos como forma de garantir a sua empregabilidade (ZANON, 2019) que é definido por Hillagee Pollard (1998, p. 12) como:

A capacidade de se mover de forma autossuficiente dentro do mercado de trabalho para realizar o potencial através do emprego sustentável. Para o individual, a empregabilidade depende dos conhecimentos, habilidades e atitudes que eles possuem, eda forma como usam esses ativos e apresentá-los aos empregadores.

O termo é fundamental para entendermos a afeição ao risco e a empreendimentos com grande chance de dar errado como é o caso das startups. A empregabilidade se confunde com a própria personalidade e a sensação é que eles devem se garantir emum mundo onde sempre há uma colocação para os "qualificados". O conceito parte de uma realidade individual e escamoteia muitos aspectos centrais do capitalismo, como consciência de classe, exploração, desigualdades e flexibilização das relaçóes trabalhistas.

Este aspecto ideológico vinculado ao conceito empregabilidade torna possível a hegemonia necessária para racionalizar este novo tipo de trabalhador, tal como Gramsci destacava no clássico Americanismo e Fordismo (2001). O fordismo perpassava o espaço da fábrica e abrangia uma faceta cultural dos trabalhadores e somente assim foi viável para o modelo alcançar a hegemonia. Para assegurar a disciplina necessária ao empreendedorismo inovador, a racionalização do processo de trabalho combina a força com relações trabalhistas cada vez mais flexíveis e a persuasão com as possibilidades de êxito na carreira.

$\mathrm{O}$ aspecto relacionado à persuasão foi acentuado com a ascensão de startups de sucesso e de jovens ficando milionários no processo. Entretanto, a possibilidade de se enriquecer com o empreendedorismo não é novae foi base do próprio capitalismo.No caso das startups um novo 
elemento entra em cena: a capacidade de ficar rico "fazendo o bem". Este aspecto - que pode ser visto como um movimento de resistência ao capitalismo de shareholder - consolida seu novo "espírito" ou "adaptação psicofísica" mencionada por Gramsci (2001).

O Facebook em si é um exemplo de como a ideologia do empreendedor de startup se espraiou a nível mundial. A ascensão de Mark Zuckerberg como um dos mais novos bilionários do mundo com história contada no filme $A$ rede social (2010) foi simbólica, pois se assemelha às velhas histórias de empreendedorismo visionário, no estilo de Henry Ford, John Davison Rockefeller e Pierre Samuel du Pont, embora com uma roupagem diferente:um jovem estudanteque cria um negócio próprio usando "apenas" uma ideia inovadora e seu computador. A diferença de Zuckerberg para os outros empreendedores é que sua empresa tem como missão "aproximar as pessoas". O criador do Facebook não é visto com a mesma carga simbólica negativa associada a um capitalismo predatório, como um banqueiro, dono de petroleira ou indústria química, sim um capitalista que está a serviço do "bem comum": um "revolucionário" que utiliza a tecnologia para mudar o mundo.

Mesmo que esta mítica não seja comprovada em um teste de realidade, a ideologia por trás das startups segue ganhando coraçôes e mentes, inclusive levando o Príncipe Harry da realeza britânica ${ }^{16}$ a buscar trabalho em uma startup com o discurso de ajudar "a criar um impacto na vida das pessoas" (FOLHA DE S. PAULO, 2021, online). A possibilidade de mudar o mundo desde uma garagem atingiu em cheio um mercado dejovens saturados com longas jornadas e trabalhos enfadonhos. Ainda que muitos enxergassem suas funçóes como criativas, dentro de suas capacidades e com remuneração adequada, o que faziam não os preenchia em sua completude. Eles vêem o seu dia a dia como uma rotina de estresse, burocracia, horários, chefes, reunióes intermináveis, código de vestimentas, metas, time sheet e etc. De uma hora para outra, há um mundo diferente lá fora: um mundo sem nenhumas das afliçóes da rotina em grandes empresas e com a possibilidade ainda de ser o próprio chefe. A frase do maior recrutador de startups, Tallis Gomes, é bem esclarecedora neste sentido:

\begin{abstract}
Cansei de tirar pessoas que trabalham em grandes empresas renomadas para virem trabalhar comigo ganhando a metade do que ganharam. E sempre me perguntam como eu consigo tanta gente boa pagando táo barato. E explico que eles não estão vendo valor que estão recebendo em dinheiro. Eles estão vendo valor em crescimento profissional, em experiência. E aí eles saem de uma empresa, na qual sua principal função era fazer power point e excel, e se mudam para uma empresa que tem como propósito de vida entregar um bem maior para a sociedade (FERNANDES, 2018, online).
\end{abstract}

Estes jovens têm um perfil sui generis: são altamente qualificados ${ }^{17}$, com curso superior e pós graduação, não raro até em instituições internacionais. Todavia, o que torna este segmento singular

\footnotetext{
16 Não se pode comparar o Príncipe Harry a massa de empreendedores inovadores sendo chief impact officer. O ponto é que de sua cooptação pelo discurso: um representante da monarquia que escolhe um emprego com um "sentido" de propósito de fazer o bem.

17 Segundo a pesquisa Raio X dos Founders (2019), com base no perfil de fundadores de startup no Brasil, 100\% tem curso superior, sendo $50 \%$ em nível de pós graduação no Brasil e exterior. As instituiçōes estrangeiras ganham mais destaque, principalmente Stanford, renomado berço de empreendedores.
} 
é que muitos desistem de bons empregos ${ }^{18}$, com direitos e alta remuneração, para se aventurar no mundo do empreendedorismo inovador, ganhando menos, muitas vezes investindo recursos próprios, trabalhando durante anos sem salário algum ${ }^{19}$ por um propósito maior que se contrapóe ao trabalho sem sentido em empresas tradicionais.Em uma simples busca no Google, se pode verificar um imenso número de casos de "jovens que largaram o emprego para montar uma startup".

Em suma, o modelo "startup de produção" soube muito bem cooptar jovens prometendo um trabalho com um sentido e a possibilidade de fazer a diferença. Mas o que estes jovens encontram ao se aventurar no mundo das startups é uma realidade inteiramente diferente dos discursos inovadores. Vemos que poucos têm realmente a chance de mudar o mundo, dado que as chances de sucesso de uma startups são mínimas. Um estudo conduzido pelo pesquisador Shikhar Ghosh, da Harvard Business School, indica que três de quatro startups falham (apud BLANK, 2013, p. 4). Os que conseguem não o fazem sozinho, pois muitas vezes dependem de investidores anjo ${ }^{20}$ ou fundos joint venture, que acabam se tornado novos chefes (BRUNO, 2018).

\section{O OUTRO LADO DAS STARTUPS}

Até o momento, foi demonstrado como o modelo de empreendedorismo de startup contribui para a visão de um modelo de capitalismo que se assemelha ao mencionado pelo Fórum Econômico Mundial como capitalismo de stakeholder e também para uma nova concepção do próprio modo de produção, em um sentido mais revolucionário ligado a "fazer o bem" usando novas tecnologias em contraposição a empresas que só pensam nos lucros.

Ao contrastar com a realidade,é possível auferir que as startups estão distantes de representar a mudança que é tão almejada por seus empreendedores. O efeito imediato das forças disruptivas que as startups representam são desigualdade social, destruição em massa de direitos e principalmente ampliando a precariedade a que estáo submetidos os trabalhadores, principalmente, nas plataformas como Uber e Ifood. Ainda que os empreendedores de startups não se encaixem nas condiçóes dos trabalhadores de plataforma e nem de precariedade, no sentido da pauperização econômica, eles também sentem os efeitos das novas formas de acumulação do capital que é qualificado na literatura contemporânea como "precarização social do trabalho" (DRUCK, 2011), no sentido de que eles nâo sofrem das mesmas condiçôes econômicas dos trabalhadores de plataforma, mesmo assim, o empreendedorismo inovador padece de precariedades semelhantes no tocante a direitos trabalhistas, longas jornadas, falta de estabilidade e de aposentadoria, entre outros benefícios.

É importante deixar claro que a precarização não é um fenômeno que surgiu com o advento das startups e das novas plataformas, mas de um fenômeno inerente ao capitalismo. Graça Druck (2011, p. 11) tem uma definição que deixa compreensível este aspecto estruturante: "precarização social do trabalho é um novo e velho fenômeno, por que é diferente e igual, por que é passado e presente e por que é um fenômeno macro e micro social”. Mesmo assim, diante da constatação que o fenômeno é uma condição sine qua non do próprio capitalismo, ela é mais utilizada para explicar o desenlaces das dinâmicas da acumulação flexível, colocada como "estruturante das relaçóes sociais

\footnotetext{
18 Em relação à experiência, a Raio X dos Founders (2019), destaca que 44,4\% tiveram experiência no mundo profissional antes da criação das empresas, tendo trabalhado em média 6,2 anos.

19 A pesquisa Lado A, Lado B - startups de 2015, desenvolvida pelo SEBRAE-SP, com o objetivo de estudar o ecossistema das startups, em Sáo Paulo, encontrou que $80 \%$ dos empreendedores começaram a empresa com recursos próprios, 50\% ficam sem salário por cerca de dois a três anos.

20 O investidor anjo é uma pessoa física que investe na startup em sua fase inicial e ainda auxilia em todo o desenvolvimento da empresa. Não se trata apenas de um investimento financeiro, sua atuaçáo se dá agregando conhecimento e redes de relacionamento, como se fosse um mentor.
} 
do capitalismo contemporâneo" (LIMA, OLIVEIRA, 2017, p.135). Neste contexto foi inserido um "novo" tipo de trabalhador: a camada média do proletariado urbano, formada por jovens que, embora altamente escolarizados, ainda se encontram inseridos em relaçóes laborais precárias em contraposição as condiçóes fordistas de direitos trabalhistas, estabilidade, previdência etc. retratada por Guy Standing (2014) em O precariado: a nova classe perigosa sobre trabalhadores europeus na ascensão do Toyotismo.

Desde os anos 1970, o sistema capitalista vem sofrendo transformações significativas no campo do trabalho ligadas à mundialização do capital e à paulatina hegemonia do capital financeiro em contraposição ao capital industrial. A flexibilização e adesregulamentação dos direitos dos trabalhadores foram exigências de um mundo cada vez mais dominado pelas finanças que visam a lógica especulativa (GUTTMANN, 2008), ou seja, do capitalismo de shareholder. O curto prazo se transformou em ordem do dia e o trabalho foi submetido a certas condiçóes para atender esse ritmo que exige mudanças rápidas quando o dinheiro se move a nível mundial na velocidade de um clique. É possível entender a precarização, surgida no ocaso do fordismo, como base ideológica para o discurso do empreendedorismo que foi capaz de fazer com que estas novas condiçóes fossem vistas como inexoráveis e, em alguns casos, como atributos positivos para estimular as potencialidades dos indivíduos (ROSENFIELD, 2011). Esta concepção ideológica oculta o caráter nocivo da precarização e pode ser visualizado no discurso empreendedor como uma etapa obrigatória para o sucesso.

A bibliografia que associa o empreendedorismo de startup à precarização ainda é incipiente no Brasil e a maior parte da literatura tem o foco nas relaçóes precárias de empreendedores tradicionais (BARBOSA; MAGNO, 2011; OLIVEIRA; MOITA; AQUINO, 2016) e em trabalhadores altamente qualificados (CASTRO, 2012; ROSENFIELD, 2011). Ainda assim, a tese da pesquisadora Breilla Zanon,Não era amor, era cilada:startups, coworkings e a mobilização do desejo pelo mundo do trabalho (2019), faz uma abrangente análise sobre como os empreendedores de startup internalizam os discursos do empreendedorismo obliterando as condiçóes de exploração e precarização, em linha com a teses aqui apresentadas.

$\mathrm{Na}$ referida tese são conduzidas entrevistas qualitativas com criadores de startupsde diferentes segmentos. Os resultados da pesquisa revelam a internalização da precarizaçáo: "os trabalhadores internalizam as demandas do capitalismo flexível, possibilitando que a instabilidade e a fragilidade que é inerente desse momento do trabalho seja diluída em seus sentidos de autorrealização" (ZANON, 2019, p.171). Esta "autorrealização" está vinculada a uma valorização das fragilidades através de um sentido que este trabalhador dá as suas atividades. As contradiçóes relacionadas à flexibilização não são percebidas como atreladas ao capitalismo pois os sujeitos "tornam-se" responsáveis de seus destinos e empresários de si mesmos, aparentemente permanecendo autônomos em relação as imposiçôes do sistema.

Em uma das entrevistas estacondiçãose dá pela "transformação da aparência da alienação" (ZANON, 2019, p. 157), e fica exemplificada pelo seguinte trecho:

E aí por ser um pouco menor [a empresa], as pessoas veem 'eu faço diferença'... dá aquele sentimento de: tá eu não sou dono, mas eu posso lidar como se fosse, porque eu gosto desse lugar e eu vou ser reconhecido (ZANON, 2019, p. 157). 
Este "lidar como se fosse" é a introjeção de uma necessidade do capitalismo de maior produtividade e do aumento da intensificação do trabalho, que coloca a cobrança de efetividade e do sucesso nas costas dos próprios empreendedores.

Com base na literatura analisada, vemos que os empreendedores de startups compartilham muitas das condiçóes do trabalho de plataforma no sentido da flexibilização, ausência de direitos e segurança. A precariedade dos empreendedores está relacionada a um processo de invisibilidade da exploraçáo que passa a ser desconhecida como tal e compreendida e legitimada pelo discurso da empregabilidade com efeitos poderosos, uma vez que transformam o mundo do trabalho "fazendo tábua rasa das conquistas sociais e econômicas resultantes de cem anos de lutas sociais, descritas como arcaísmos e obstáculos à nova ordem nascente" (BOURDIEU; WACQUANT, 2013, p. 82).

\section{CONSIDERAÇÕES FINAIS}

O intuito durante todo o percurso teórico foi demonstrar como as startups, que se colocam como um elemento disruptivo aliando o discurso do empreendedorismo à inovação tecnológica, podem ser associadas ao modelo de capitalismo preconizado por este great reset. A associação ocorre, principalmente, porque as startups buscam representar ideologicamente uma noção diferente de empresa e ao mesmo tempo fazem uso das tecnologias como forma de solucionar problemas reais e "mudar o mundo".

As subjetividades dos empreendedores inovadores vêm sendo mobilizadas pelo componente ideológico das startups e reforçam o seu enquadramento ao capitalismo de stakeholder. Esse novo tipo de trabalho se destaca como forma de "fazer o bem"e a alienação parece não existir, pois "se reconhecem no produto e no processo de seu trabalho e se realizam por meio deles" (ZANON, 2019, p. 171). Porém, conforme demonstrado, a exploração se mantém por trás da roupagem inovadora, jovem, empreendedora, livre e cheia de propósitos. Ainda, é possível encontrar, sob todo este manto ideológico, modos de extração de mais-valia que se diferenciam em sua aparência, mas não em sua essência.

Não é possível terminar o artigo sem destacar a importância deste modelo de empresa que, mesmo sob o manto da precarizaçáo social, realiza formas ocultas de exploraçáo e concepçáo de sucesso distante da realidade. As startups são de fundamental importância para o setor de inovação e continuarão crescendo e revolucionando mercados (THIEL, 2014). Como é possível, a partir deste cenário, buscar um desenvolvimento sustentável que alie a inovação e desmistifique o caráter exploratório das relaçóes trabalhistas ensejadas por este novo modelo?

A resposta com certeza não partirá de uma recriação do movimento Ludista em relação às novas tecnologias. Pelo contrário, se faz necessário buscar formas de contornar os aspectos deletérios e usar a tecnologia a favor das demandas sociais. Neste aspecto, o professor Antonio Casilli (2021) da Paris School of Telecommunications faz uma análise do contexto atual, traçando cenários possíveis para o futuro. O primeiro cenário destacado pelo pesquisador francês é um movimento que vem ganhando cada vez mais força, que é o enquadramento das empresas, principalmente aquelas vinculadas ao trabalho de plataforma, nos marcos legais. No momento em que escrevo estas linhas a Uber acaba de acatar, parcialmente, uma decisão da suprema corte do Reino Unido e vai reclassificar seus motoristas como empregados com direito a salário mínimo, férias e até um esquema de aposentadoria ligado à empresa (LEE; STRAUSS, 2021). Ainda é cedo para saber o impacto desta decisão para os trabalhadores e, consequentemente, para o futuro da empresa, pois essa decisão, segundo a lógica do capital, poderá encarecer os serviços e torná-los inviáveis do ponto de vista financeiro. Não obstante, é importante salientar que as estruturas estão se alteando muito devido aos processos de luta (BRAGA, 2009). 
Outro cenário mencionado é a utilização das plataformas como forma de cooperativas para unificar trabalhadores que utilizariam a tecnologia com ponte. Vejamos um exemplo simples de como isso funcionária. A pandemia do COVID-19 e as políticas de confinamento evidenciaram muitas disparidades e dificuldades para micro e pequenos empresários. Ao mesmo tempo em que há pessoas passando fome nas periferias das grandes cidades, pequenos agricultores acabam tendo que jogar fora seus estoques pela falta defeiras para a comercialização dos seus produtos. Neste caso, uma cooperativa de plataforma seria interessante para uma melhor utilizaçáo dos alimentos.

Vemos que ainda há espaço para o romantismo de "mudar o mundo" com uma ideia inovadora. Da mesma forma abusca por um trabalho com sentido ao seu trabalho não pode ser perdida, no entanto, é importante criar um entendimento de que, mesmo qualificados, os empreendedores inovadores não estão imunes a exploração. É preciso criar umaconsciência de classe que abarque formas de preservação de direitos e que seja possível entender que a suaausência é na verdade uma exigência do capitalismo contemporâneo e não uma realidade inexorável.

\section{REFERÊNCIAS}

ALVES, Giovanni. Dimensóes da Reestruturaçáo Produtiva - Ensaios de sociologia do trabalho. Bauru: Editora Praxis, 2007.

ANDRADE, Daniel Pereira. O que é o neoliberalismo? A renovação do debate nas ciências sociais. Revista Sociedade e Estado, [s.l.], vol. 34, n. 1, p.211-239, 2019.

ANTUNES, Ricardo; FILGUEIRAS, Vitor. Plataformas digitais, Uberização do trabalho e regulação no Capitalismo contemporâneo. Contracampo, Niterói, [s.l.], vol. 39, n. 1, p. 27-43,2020.

A REDE SOCIAL; Direção: David Fincher. Produção: Relativity Média. Estados Unidos: Columbia Pictures, 2010. 1 DVD (120 min.)

BANCO MUNDIAL. Do plano ao mercado. Washington, 1996.

BARBOSA, Silva; MAGNO, Attila. O empreendedor de si mesmo e a flexibilização no mundo dotrabalho. Revista de Sociologia e Política, [s.l.], vol. 19, n. 38, p. 22, 2011.

BARBROOK, Richard; CAMERON, Andy. The Californian Ideology. Science as culture, [s.l.], vol. 6, n. 1, p. 44-72, 1996.

BICUDO, Lucas. (2016) Afinal, O que é uma Startup? Startse Infomoney, São Paulo. Disponível em: $<$ https://www.startse.com/noticia/startups/18963/afinal-o-que-e-uma-startup >. Acesso em: 09 fev. 2021.

BIHR, Alain. Maio-junho de 1968 na França, o epicentro de uma crise de hegemonia (parte I). Mediaçóes, [s.l.], vol. 12, n. 2, p. 19-54, jul/dez. 2007.

BLANK, Steven. Why the lean Startup changes everything? Harvard Business Review, [s.l.], vol. 91,n.5, p. 63-72,2013.

BLANK, Steve; DORF, Bob. The Startup owner's manual: the step-by-step guide for building agreat company. K\&S Ranch, 2012. 
BOURDIEU, Pierre; WACQUANT,Löic. O imperialismo da razão neoliberal. Sociologia em Rede, [s.l.], vol. 3, n. 3, p. 82-87, 2013.

BRAGA, Ruy. A vingança de Braverman: o infotaylorismo como contratempo. In: BRAGA, Ruy; ANTUNES, Ricardo (orgs.). Infoproletários: degradaçáo real do trabalho virtual. Sáo Paulo: Boitempo, v.1, 2009.

BRUNO, Luciana. Empreendedores de startups e trabalho imaterial no capitalismo cognitivo. Dissertação (Mestrado em Ciência da Informação), Instituto Brasileiro de Informação em Ciência e Tecnologia / Universidade Federal do Rio de Janeiro, Rio de Janeiro, 2018.

CASILLI, Antonio. Entrevista concedida a Digilabour. A uberização é só um dos aspectos do trabalho em plataformas: entrevista com Antonio Casilli. Digilabour, laboratório de pesquisa. Edição online. São Paulo, SP, [03/07/2019]. Disponível em: <https://digilabour.com.br/2019/06/03/casilli-a-uberizacao-e-so-um-dos-aspectos-do-trabalho-de-plataforma/>. Acesso em 29 de mar 2021.

CASTRO, Bárbara. Afogados em contratos: o impacto da flexibilização do trabalho nas trajetórias dos profissionais de TI.Tese (Doutorado em Ciências Sociais), Instituto de Filosofia e Ciências Humanas / Universidade Estadual de Campinas, Campinas, SP.2012.

CHESNAIS, Françoais. A mundializaçáo do capital. São Paulo: Xamã, 1996.

DAL ROSSO, S. Mais trabalho! A intensificaçáo do labor na sociedade contemporânea. São Paulo:Boitempo, 2008.

D'ANDRETA, Mario. Davos discourse drives cultural hegemony. Transnational Institute (TNI). Corporate Power. 2018. Disponível em: <https://www.tni.org/es/node/23882>. Acesso em jun 2018.

DARDOT, Pierre; LAVAL, Christian. A nova razáo do mundo: ensaio sobre a sociedade neoliberal. São Paulo: Boitempo, 2016.

DELEUZE, Giles.; GUATTARI, Félix. O Anti-édipo. Tradução Luiz B. L. Orlandi. 2. ed. São Paulo: Editora 34, 2011.

DOWBOR, Ladislau. O capitalismo se desloca: novas arquiteturas sociais. São Paulo: ediçôes SESC São Paulo, 2020.

DRUNK, Graça. TRABALHO, PRECARIZAÇÃO E RESISTÊNCIAS: novos e velhos desafios? Caderno Crh, Salvador, vol. 24, n. SPE 01, p. 9-13, 2011.

Estudo SEBRAE-SP.LADO A, LADO B DAS STARTUPS. 2015 Disponível em: < https://www.sebrae.com. br/Sebrae/Portal\%20Sebrae/UFs/SP/Pesquisas/lado_A B startups.pdf.>Acesso em: mar, 2021.

FAVARETTO, Sonia Consiglio. Capitalismo de Stakeholder, Consciente, Responsável, Sustentável... Vamos simplificar?Valor investe. Blogs. Rio de Janeiro: Grupo Globo, [06/10/2020]. Disponível: <https://valorinveste.globo.com/blogs/sonia-favaretto/post/2020/10/capitalismo-de-stakeholder-consciente-responsavel-sustentavel-vamos-simplificar.ghtml>. Acesso em: mar, 2021. 
FERNANDES, Daniel. Por que jovens brilhantes estão largando bons empregos para empreender e o que as empresas deveriam fazer para (não) retê-los. Blog do empreendedorismo. Estadão. Blogs. São Paulo: Grupo Estado. [13/04/2018]. Disponível em: <https://pme.estadao.com.br/blogs/blog-do-empreendedor/ por-que-jovens-brilhantes-estao-largando-bons-empregos-para-empreender/>. Acesso em mar, 2021.

FOLHA DE SÃO PAULO. Príncipe Harry aceita emprego novo: diretor de impacto da BetterUp.Folha de São Paulo. Celebridades. São Paulo: Grupo Folha, [23/03/2021]. Diário. Disponível em: <https://f5.folha. uol.com.br/celebridades/2021/03/principe-harry-aceita-emprego-novo-diretor-de-impacto-da-betterup. shtml>. Acesso em: 29mar 2020.

FONTES, Virgínia. Capitalismo em tempos de uberização: do emprego ao trabalho. Marx e o Marxismo, vol.5, n.8, jan/jun 2017.

GITAHY, Yuri. O que é uma startup? Exame, São Paulo: [2016]. Disponível em: <http://exame.abril.com. br/pme/o-que-e-uma-startup/>. Acesso em: 26mar. 2021.

GORZ, André. Imaterial (0)-conhecimento, Valor. São Paulo: Annablume, 2005.

GRAMSCI, Antônio. Cadernos do cárcere, vol. 4. Edição e tradução Carlos Nelson Coutinho. Rio de Janeiro: Civilização Brasileira, 2001.

GUTTMANN, Robert. Uma introduçáo ao capitalismo dirigido pelas finanças. Novos Estudos CEBRAP, São Paulo-SP, n. 82, p. 11-33, nov. 2008.

HARVEY, David. Condiçáo Pós-Moderna. São Paulo: Edições Loyola, 1992.

HARVEY, David. O neoliberalismo: história e implicaçóes. São Paulo: Ediçóes Loyola, 2014.

HILLAGE, Jim. and POLLARD, Emma. Employability: Developing a Framework for Policy Analysis. London: DfEE. 1998.

IANNI, Octavio. Globalização e Neoliberalismo. Sáo Paulo em perspectiva, São Paulo, vol. 12, n. 2,1998.

KATZ, Claudio. Neoliberalismo, neodesenvolvimentismo, socialismo. Expressão popular: Perseu Abramo, 2016.

LEE, Dave. STRAUSS, Delphine. Uber define motoristas como trabalhadores do app no Reino Unido. Folha de São Paulo. Mercado. São Paulo: Grupo Folha, [16/03/2021]. Diário. Disponível em: <https:// www1.folha.uol.com.br/mercado/2021/03/uber-aceita-mudancas-cruciais-e-define-motoristas-como-funcionarios-no-reino-unido.shtml>. Acesso em: mar, 2021.

LIMA, Jacob Carlos. OLIVEIRA, Daniela Ribeiro. Trabalhadores digitais: as novas ocupaçōes no trabalho informacional. Soc. estado, [s.l.], vol. 32, n. 1, 2017.

LOURES, Hamilton Lopes. Empreendedorismo: uma visão política de seus fundamentos. Negócios em Projeçáo, Brasília, vol. 6, n. 2, p. 93-104, 2015. 
MANZONI, Leandro. As 10 maiores operações de fusões e aquisiçốes da história. FORBES. Negócios. São Paulo: Forbes Brasil, [14/12/2017]. Disponível: <https://forbes.com.br/negocios/2017/12/as-10-maiores-operacoes-de-fusoes-e-aquisicoes-da-historia/\#foto9>. Acesso em: mar 2021.

MARX, Karl. Manuscritos econômico-filosóficos. São Paulo: Martin Claret, 2005.

NORMAND, Reinaldo. Vale do Silício: entenda como funciona a região mais inovadora do planeta. 2014. Disponível em: <http://www.valedosilicio.com>. Acesso em: jun 2021.

OLIVEIRA, Eveline Nogueira Pinheiro; MOITA, Dimitre Sampaio; AQUINO, Cassio Adriano Braz. O Empreendedor na Era do Trabalho Precário: relaçóes entre empreendedorismo e precarização laboral. Psicologia Política. [s.l.], vol. 16. no 36. pp. 207-226, 2016.

PAYÃO, Felipe. O Facebook tem uma nova missão, segundo Zuckerberg. TECMUNDO. Disponível em: <https://www.tecmundo.com.br/facebook/118182-facebook-tem-nova-missao-segundo-zuckerberg.htm >. Acesso em: 31 mar. 2021.

PRADO, Eleutério. Desmedida do valor: crítica da pós-grande indústria. São Paulo: Xamã, 2005.

PRADO, Eleutério F. S.; PINTO, José Paulo Guedes. Subsunção do trabalho imaterial ao capital.Caderno CRH, Salvador, v. 27, n. 70, p. 61-74, 2014.

RAIO X DOS FOUNDERS. Estudo ACE Startups. São Paulo, 2019

RIFKIN, Jeremy. A Terceira Revoluçáo Industrial Como o Poder Lateral está Transformando a Energia, a Economia e o Mundo. São Paulo: M.Books, 2002.

ROSENFIELD, Cínara L. Trabalho decente e precarização. Tempo Social,[s.l.], vol. 23, n. 1, p. 247-268, 2011.

SAVAGE, Sam. The Generation Z Connection: Teaching Information Literacy to the Newest Net Generation. Red Orbit, Nashville, TN, USA. [19/02/2006]. Technology. Disponível em: <https://www.redorbit.com/ news/technology/397034/the_generation_z_connection_teaching_information_literacy_to_the_newest/>. Acesso em: jun, 2021.

SCHWAB, Klaus. A quarta revoluçáo industrial. São Paulo: Edipro, 2016.

SCHWAB, Klaus. What Kind of Capitalism Do We Want?Project Syndicate. 2019. Disponível em: <https:// www.project-syndicate.org/commentary/stakeholder-capitalism-new-metrics-by-klaus-schwab-2019-11>. Acesso em: jun. 2021.

Now is the time for a 'great reset'. World Economic Forum. 2020. Disponível em: <https://www.weforum.org/agenda/2020/06/now-is-the-time-for-a-great-reset/>. Acesso em: jun. 2021.

VANHAM, Peter. Stakeholder Capitalism: A Global Economy that Works for Progress, People and Planet. Hoboken, New Jersey (USA): John Wiley \& Sons, Inc. 2021.

KROSS, Hein. Modern Company Management in Mechanical Engineering. Maschinenbau-VerlagGmbH, 1971. 
SILVA JUNIOR, Humberto Alves. Indústria cultural e ideologia. Caderno CRH, Salvador, vol.32, n.87, p.505-516, 2019.

STANDING, Guy. O precariado: a nova classe perigosa. Belo Horizonte: Autêntica Editora, 2014.

STUBBINGTON, Tommy. Global debt surges to highest level in peacetime. Financial Times. Londres (Inglaterra): Financial Times Group. [25/09/2019]. Disponível em: <https://www.ft.com/content/661f5c8a-dec9-11e9-9743-db5a370481bc>. Acesso em: jun 2021.

SIQUEIRA, Mauricio; COCCO, Giuseppe (orgs.). Por uma política menor: arte, comum e multidão. Rio de Janeiro: Fundação Casa de Rui Barbosa, 2014.

THIEL, Peter; MASTERS, Blake. Zero to one: notes on startups or how to build the future. New York: Crown Bussiness, 2014. 160 p.

WORLD ECONOMIC FORUM. Improving the state of the world.Disponível em: https://www.weforum.org/our-impact. Acesso em: 18 jun. 2021.

ZANON, Breilla. "náo era amor, era cilada": startups, coworkings e a mobilização do desejo pelo mundo do trabalho. Tese (Doutorado em Sociologia), Programa de pós-graduação em sociologia / Universidade Federal de São Carlos, São Carlos, 2019.

Essa pesquisa foi realizada durante o período de pesquisa de doutorado do autor. A pesquisa de doutorado foi financiada pela Coordenação de Apoio ao Pessoal de Nível Superior (CAPES), processo 88887.512478/2020-00. 